\title{
Variabilidade genética em germoplasma tradicional de feijão-preto em Santa Catarina
}

\author{
Haroldo Tavares Elias ${ }^{(1)}$, Maria Celeste Gonçalves Vidigal(2), Adriana Gonela ${ }^{(2)}$ \\ e Gilcimar Adriano Vogt ${ }^{(1)}$
}

\begin{abstract}
(1)Empresa de Pesquisa Agropecuária e Extensão Rural de Santa Catarina, Centro de Pesquisa para Agricultura Familiar, Caixa Postal 791, CEP 89801-970 Chapecó, SC. E-mail: htelias@epagri.sc.gov.br, gilcimar@epagri.sc.gov.br (2)Universidade Estadual de Maringá, Dep. de Agronomia, Av. Colombo, no 5.790, CEP 87020-900 Maringá, PR. E-mail: mvidigal@pop.br, adriana_g35@yahoo.com.br
\end{abstract}

Resumo - O objetivo deste trabalho foi avaliar a diversidade genética entre 45 cultivares de feijões tradicionais do grupo comercial preto, por meio de técnicas multivariadas baseadas em 11 caracteres morfoagronômicos e nutricionais. A distância generalizada de Mahalanobis fundamentou as técnicas de agrupamentos Tocher e UPGMA. Pelo método Tocher foram constituídos nove grupos. Foi detectada divergência genética entre as cultivares tradicionais e as testemunhas comerciais de feijão. A maior divergência foi observada entre as cultivares do grupo 7, em especial a cultivar CFE 22, que se apresentou mais divergente em relação às demais. Para compor programas de hibridação com os genótipos avaliados, sugerem-se cruzamentos entre as cultivares do grupo 2, em especial CFE 25, CFE 100 e FT Nobre, e as do grupo 7, em especial o acesso CFE 22. Essas cultivares se destacam por serem as mais divergentes entre si e por possuírem as melhores produtividades.

Termos para indexação: Phaseolus vulgaris, divergência genética, distância de Mahalanobis, técnicas de agrupamento.

\section{Genetic variability in traditional germplasm of common black beans in Santa Catarina State, Brazil}

\begin{abstract}
The objective of this work was to evaluate the genetic diversity through eleven morphological, agronomic and nutritional characteristics, among 45 traditional cultivars of common black beans collected in Santa Catarina, Brazil. Genetic divergence was detected among traditional and commercial test cultivars. The generalized distance of Mahalanobis was the basis for Tocher and UPGMA clusters. By the Tocher method, nine groups were constituted and the greatest divergences were observed among the cultivars of the group 7 , specially cultivar CFE 22. To compose breeding program with these groups of genotypes, it is suggested crossings among cultivars of the group 2 , mainly with CFE 25 , CFE 100 , FT Nobre, and those of the group 7, specially cultivar CFE 22. These cultivars were the most divergent and productive ones.
\end{abstract}

Index terms: Phaseolus vulgaris, genetic divergence, Mahalanobis distance, cluster techniques.

\section{Introdução}

O feijão (Phaseolus vulgaris L.) é o alimento proveniente de leguminosas mais difundido do mundo, por ser uma importante fonte de proteínas e calorias para mais de 500 milhões de pessoas na América Latina e África (FAO, 2005).

O estudo de características morfológicas e agronômicas das plantas cultivadas é importante para se conhecer a divergência genética do conjunto de germoplasma disponível para fins de utilização em programa de melhoramento genético.
Existem duas maneiras de se inferir sobre a diversidade genética: de forma quantitativa e de forma preditiva. Entre as de natureza quantitativa, citam-se as análises dialélicas, nas quais são necessários os cruzamentos entre os genitores e sua posterior avaliação. As de natureza preditiva têm por base as diferenças morfológicas, de qualidade nutricional, fisiológicas ou moleculares, quantificadas em alguma medida de dissimilaridade que possa expressar o grau de diversidade genética entre os genitores (Cruz \& Carneiro, 2003).

A utilização de técnicas multivariadas para estimar a divergência genética tem se tornado comum, é 
empregada em vários trabalhos e em diversas culturas, tais como eucalipto (Scapim et al., 1999), milho (Melo, 2001) e feijão (Ribeiro et al., 2001; Bonett et al., 2006; Ceolin et al., 2007).

Quando diversos caracteres de diferentes genótipos são medidos simultaneamente, aos pares, as distâncias de Mahalanobis $\left(\mathrm{D}^{2}\right)$ podem ser tomadas como estimativas de diversidade genética entre eles. Essa diversidade é obtida segundo diferenças fisiológicas, morfológicas e agronômicas, avaliadas a partir de um grupo de genótipos.

A viabilidade da utilização da divergência genética como critério de seleção de genitores tem sido relatada por diversos autores (Franco, 2001; Santos, 2005; Ceolin et al., 2007). A correlação positiva entre a divergência e a heterose é indicativa da eficiência da predição do comportamento dos híbridos, em várias culturas, tais como feijão (Ghaderi et al., 1984) e milho (Ferreira, 1993).

De acordo com Ferreira (1993), quando correlações residuais significativas entre os diversos caracteres são identificadas, deve-se preferencialmente utilizar a distância de Mahalanobis.

Muitos têm sido os métodos propostos para análise de agrupamento (conglomeração), entretanto, os mais utilizados no melhoramento de plantas são os hierárquicos e os de otimização de Tocher. Outro método que tem sido muito utilizado é o UPGMA. Neste método, o critério utilizado para a formação dos grupos é a média das distâncias entre todos os pares de itens que formam cada grupo. Em termos de melhoramento genético, Dudley (1994) refere-se ao método UPGMA como superior aos métodos do vizinho mais próximo e mais distante, quando comparados com informação conhecida de "pedigree".

Nos métodos hierárquicos, os indivíduos ou unidades amostrais, são agrupados em vários níveis até que seja constituído um dendrograma, ou diagrama de árvore. Este critério de agrupamento em dendrograma foi utilizado em trabalhos com milho (Ferreira, 1993), feijãode-vagem (Peixoto, 2002) e feijão (Emygdio, 2003).

Uma das alternativas para avaliar a divergência genética entre possíveis progenitores é a distância euclidiana, estatística multivariada que enfatiza as variações de características agronômicas, morfológicas e fisiológicas.

Entre as várias técnicas multivariadas passíveis de serem utilizadas, Cruz \& Regazzi (1997) citam as análises por componentes principais e variáveis canônicas e os métodos aglomerativos que utilizam a distância euclidiana ou a distância generalizada de Mahalanobis como medidas de dissimilaridade. Comparação entre essas técnicas tem sido demonstrada em alguns trabalhos. Santos (2005) realizou a seleção de pré-cultivares de soja baseada em índices, utilizando as técnicas de distância euclidiana e Mahalanobis, indicando maior eficiência em discriminar as linhagens quando foi utilizada a distância de Mahalanobis. A distância de Mahalanobis mostrou-se também eficiente, conforme constatado por Machado et al. (2002), por ter permitido a classificação das populações segregantes de feijão com maior potencial de variabilidade mesmo quando provenientes de genitores formados por cultivares/linhagens aparentadas. Da mesma maneira, Benin (2002) estimou a dissimilaridade genética entre genótipos de feijão, permitindo seu uso estratégico em hibridações artificiais dirigidas.

O objetivo deste trabalho foi caracterizar a divergência genética em 45 cultivares tradicionais de feijão do grupo comercial preto por meio de técnicas multivariadas, baseadas em caracteres morfoagronômicos e nutricionais.

\section{Material e Métodos}

Foram utilizadas 42 cultivares tradicionais de feijãocomum, obtidas de coletas realizadas por pesquisadores da Empresa de Pesquisa e Extensão Rural de Santa Catarina (Epagri), na década de 1990, em pequenas propriedades rurais do Estado de Santa Catarina.

As cultivares foram distribuídas em dois experimentos compostos cada um por 21 cultivares tradicionais e três cultivares comerciais (testemunhas) recomendadas para cultivo na Região Sul. Essa divisão teve como objetivo permitir a utilização de blocos menores, visando à diminuição da heterogeneidade. Os experimentos foram implantados em área experimental contígua, o que permitiu supor a não-existência da interação experimentos $\mathrm{x}$ tratamentos.

O delineamento experimental utilizado foi o de blocos ao acaso com três repetições. Os experimentos foram instalado na área da Epagri, Município de Chapecó, situado na região oeste de Santa Catarina, a $27^{\circ} 7 \mathrm{~S}$ e $52^{\circ} 37^{\prime} \mathrm{W}$, altitude de $679 \mathrm{~m}$ em três épocas: safra 2002/ 2003, safrinha 2003 e safrinha 2004. A parcela foi formada por quatro linhas de $4 \mathrm{~m}$, espaçadas em $0,45 \mathrm{~m}$, sendo a área útil composta pelas duas linhas centrais. A densidade de semeadura foi de 12 sementes por metro 
linear e os tratos culturais e adubação foram realizados de acordo com as recomendações técnicas para a cultura do feijoeiro em Santa Catarina (Epagri, 1997).

As características avaliadas foram: altura de plantas (AP); número médio de vagens por planta (NVP); número médio de sementes por planta (NSP); massa de 100 grãos (P100); produtividade de grãos (Prod); comprimento longitudinal do folíolo (CF); número de dias para a maturação $(\mathrm{DM})$; teor de proteína bruta $(\mathrm{PB})$; teor de fibra bruta $(\mathrm{FB})$; reação à bacteriose crestamento bacteriano (Xanthomonas campestris pv. phaseoli (Smith) Dye (Bac); reação à antracnose (Antr).

Foram realizadas as análises de variância individuais das onze variáveis, comparadas pelo teste de médias Scott-Knott, a 5\% de probabilidade. A análise de variância multivariada, para a avaliação da variabilidade genética total existente entre as cultivares, foi realizada a partir dos dados provenientes da análise conjunta de variância, na qual se consideraram os efeitos das cultivares como fixos. A partir da análise de variância multivariada, obtiveram-se as matrizes de soma de quadrados e produtos residuais e a matriz de soma de quadrados e produtos entre cultivares. As distâncias generalizadas de Mahalanobis, obtidas a partir dos dados padronizados, foram utilizadas como medidas de dissimilaridades. No estudo de divergência genética, foram utilizados os métodos aglomerativos de Tocher e UPGMA, fundamentados na distância generalizada de Mahalanobis como medida de dissimilaridade.

\section{Resultados e Discussão}

A análise conjunta (Tabela 1) mostrou diferença significativa entre os tratamentos, para os caracteres Prod, P100, Bac, AP, NVP e PB, o que confirma a existência de variabilidade fenotípica para a maioria dos caracteres estudados. Estes resultados demonstram a existência de variabilidade entre as cultivares tradicionais e, consequientemente, a possibilidade de obtenção de ganhos genéticos em programas de melhoramento com o uso de germoplasma tradicional.

Os resultados médios das características estudadas nas 45 cultivares avaliadas encontram-se no Tabela 2. Observa-se superioridade no rendimento médio de grãos das testemunhas $\left(1.428 \mathrm{~kg} \mathrm{ha}^{-1}\right)$ em relação às cultivares tradicionais $\left(1.304 \mathrm{~kg} \mathrm{ha}^{-1}\right)$, o que reflete o esforço dos programas de melhoramento genético em feijão.

O rendimento médio de grãos nos experimentos foi de $1.312 \mathrm{~kg} \mathrm{ha}^{-1}$, sendo o maior rendimento observado na cultivar CFE 25, com $1.841 \mathrm{~kg} \mathrm{ha}^{-1}$. Além desta, as cultivares tradicionais CFE 02, CFE 18 e CFE 94 também apresentaram rendimentos superiores a $1.600 \mathrm{~kg} \mathrm{ha}^{-1}$, comparáveis às três testemunhas. Esse fato corrobora a perspectiva da utilização de germoplasma tradicional no melhoramento genético do feijão, principalmente em relação à característica rendimento de grãos, apesar de terem apresentado média geral inferior à das cultivares melhoradas.

O P100 foi o caráter que possibilitou maior discriminação entre os tratamentos pelo teste ScottKnott, ou seja, foi aquele em que se obteve o maior número de grupos significativamente diferentes entre as 45 cultivares avaliadas. Os valores para esta característica oscilaram entre 13,5 e 28,1 g por 100 grãos, o que evidencia variabilidade entre as cultivares. De acordo com Singh et al. (1989), o tamanho das sementes de feijão cultivado pode variar de menos de 15 a $90 \mathrm{~g}$ por 100 sementes e são agrupadas em pequenas $(<25 \mathrm{~g})$ e médias ( $25 \mathrm{a} 40 \mathrm{~g}$ por 100 grãos).

A maioria das cultivares foi classificada como de grãos pequenos, e apenas as cultivares CFE 25 (FC 2026) e

Tabela 1. Resumo de análise de variância agrupada e média geral das cultivares tradicionais e das testemunhas para as 11 características avaliadas das 45 cultivares de feijão do grupo Preto ${ }^{(1)}$.

\begin{tabular}{|c|c|c|c|c|c|c|c|c|c|c|c|c|}
\hline \multirow[t]{2}{*}{ Fonte de variação } & \multirow[t]{2}{*}{ GL } & \multicolumn{11}{|c|}{ Quadrados médios } \\
\hline & & $\mathrm{DM}$ & Prod & P100 & $\mathrm{Bac}$ & Antr & $\mathrm{CF}$ & AP & NVP & NSP & PB & FB \\
\hline Blocos & 2 & 1,14 & $65.090,9$ & 3,9 & 0,33 & 0,80 & 1,90 & 0,09 & 34,93 & 720,5 & 0,88 & 0,59 \\
\hline Experimento & 1 & $49,00 * *$ & $1.546 .338,3$ & 306,3 & 0,06 & 0,06 & 12,84 & 0,13 & 189,75 & $1.536,6$ & 41,70 & 0,02 \\
\hline Tratamento & 44 & $4,25 * *$ & $141.514,6^{* *}$ & $752,9 * *$ & $0,59 * *$ & $0,22^{\text {ns }}$ & $0,68^{\text {ns }}$ & $0,04 * *$ & $50,92 * *$ & $1.183,0 * *$ & $2,44 * *$ & $0,22^{\mathrm{ns}}$ \\
\hline Resíduo & 94 & 0,79 & $44.374,1$ & 13,4 & 0,32 & 0,29 & 0,56 & 0,02 & 14,31 & 242,1 & 1,20 & 0,19 \\
\hline Média geral & & 87,37 & $1.320,1$ & 17,36 & 4,10 & 3,09 & 10,62 & 0,85 & 16,54 & 76,8 & 21,38 & 4,37 \\
\hline Média das cultivares & & 87,45 & $1.304,5$ & 17,54 & 4,07 & 3,10 & 10,65 & 0,86 & 16,63 & 76,9 & 21,38 & 4,38 \\
\hline Média testemunha & & 86,83 & $1.428,8$ & 16,08 & 4,33 & 3,00 & 10,46 & 0,77 & 15,91 & 76,0 & 21,40 & 4,29 \\
\hline $\mathrm{CV}(\%)$ & & 1,02 & 15,9 & 4,2 & 13,71 & 17,3 & 7,02 & 15,38 & 22,87 & 20,2 & 5,12 & 10,13 \\
\hline
\end{tabular}

${ }^{(1)} \mathrm{GL}$ : graus de liberdade; DM: dias para maturação; Prod: rendimento de grãos; P100: peso de 100 grãos; Bac: reação à bacteriose; Antr: reação à antracnose, CF: comprimento do folíolo; AP: altura da planta; NVP: número de vagens por planta; NSP: número de sementes por planta; PB: proteína bruta; FB: fibra bruta. * e **Significativo a 5 e $1 \%$ de probabilidade, respectivamente, pelo teste $\mathrm{F}$. 
CFE 100 (FC 113) como de grãos médios. O caráter PB apresentou média geral de 21,38\%, e amplitude de variação de $4,1 \%$ (Tabela 2). Avaliações do teor de proteína de cultivares tradicionais foram realizadas por Silva \& Iachan (1975), que observaram valor médio de $21,9 \%$ em 33 cultivares. Vidigal Filho et al. (2003) obtiveram o percentual médio de proteína de $23,1 \%$ em 25 cultivares tradicionais do Paraná, valores semelhantes aos apresentados neste trabalho. Os resultados médios do caráter DM oscilaram entre 85,8 a 89,8 dias, com pequena diferenciação entre as cultivares, já que nenhuma pôde ser classificada como precoce.

Tabela 2. Médias dos 11 caracteres avaliados nas 45 cultivares de feijão-preto, e grupos de cultivares estabelecidos pelo método de otimização Tocher com base nesses 11 caracteres, com uso da distância generalizada de Mahalanobis ${ }^{(1)}$.

\begin{tabular}{|c|c|c|c|c|c|c|c|c|c|c|c|c|}
\hline Cultivar & $\mathrm{DM}$ & $\begin{array}{c}\text { Prod } \\
\left(\mathrm{kg} \mathrm{ha}^{-1}\right)\end{array}$ & $\begin{array}{c}\text { P100 } \\
(\mathrm{g}) \\
\end{array}$ & Bac. & Antr & $\begin{array}{c}\mathrm{CF} \\
(\mathrm{cm})\end{array}$ & $\begin{array}{l}\text { AP } \\
(\mathrm{m})\end{array}$ & NVP & NSP & $\begin{array}{l}\text { PB } \\
(\%) \\
\end{array}$ & FB (\%) & Grupo \\
\hline CFE 08 - FC 2036 & $86,8 \mathrm{c}$ & $1.284 \mathrm{a}$ & $16,20 \mathrm{e}$ & $4,11 b$ & $3,77 \mathrm{a}$ & $10,7 \mathrm{a}$ & $0,86 a$ & $12,93 \mathrm{c}$ & $59,9 b$ & $22,3 a$ & $4,83 \mathrm{a}$ & 1 \\
\hline CFE $80-$ FC 155 & $88,8 \mathrm{~b}$ & $1.367 \mathrm{a}$ & $19,10 \mathrm{~b}$ & $3,11 \mathrm{~b}$ & $3,11 \mathrm{a}$ & $10,8 \mathrm{a}$ & $1,12 \mathrm{a}$ & $19,80 \mathrm{~b}$ & $85,1 \mathrm{a}$ & $22,1 \mathrm{a}$ & $4,47 \mathrm{a}$ & 1 \\
\hline CFE $92-$ FC 178 & $86,8 \mathrm{c}$ & $1.227 \mathrm{~b}$ & $23,40 \mathrm{~b}$ & $4,22 b$ & $2,88 \mathrm{a}$ & $10,9 \mathrm{a}$ & $0,90 \mathrm{a}$ & $12,00 \mathrm{c}$ & $51,6 b$ & $20,6 b$ & $4,48 \mathrm{a}$ & 1 \\
\hline CFE $111-$ FC 38 & $89,8 \mathrm{a}$ & $1.157 \mathrm{~b}$ & $16,40 \mathrm{e}$ & $3,88 \mathrm{~b}$ & $2,88 \mathrm{a}$ & $11,0 \mathrm{a}$ & $0,97 \mathrm{a}$ & $19,40 \mathrm{~b}$ & $105,4 \mathrm{a}$ & $21,6 \mathrm{a}$ & $4,35 \mathrm{a}$ & 1 \\
\hline CFE $02-$ FC 2017 & $87,5 \mathrm{a}$ & $1.605 \mathrm{a}$ & $16,10 \mathrm{e}$ & $3,11 b$ & $3,11 \mathrm{a}$ & $11,1 \mathrm{a}$ & $1,04 \mathrm{a}$ & $32,13 a$ & $145,7 \mathrm{a}$ & $20,1 b$ & $1,30 \mathrm{a}$ & 2 \\
\hline CFE 25 - FC 2026 & $86,5 \mathrm{c}$ & $1.841 \mathrm{a}$ & $28,10 \mathrm{a}$ & $4,77 \mathrm{a}$ & $3,11 \mathrm{a}$ & $11,6 \mathrm{a}$ & $0.86 a$ & $13,60 \mathrm{c}$ & $61,5 b$ & $19,9 b$ & $4,46 a$ & 2 \\
\hline CFE 29 - FC 2062 & $85,8 \mathrm{c}$ & $1.715 \mathrm{a}$ & $17,40 \mathrm{~d}$ & $3,11 b$ & $3,11 \mathrm{a}$ & $10,1 \mathrm{a}$ & $0,62 b$ & $22,60 \mathrm{~b}$ & $100,9 a$ & $19,9 b$ & $4,40 \mathrm{a}$ & 2 \\
\hline CFE 34 - FC 2048 & $86,5 \mathrm{c}$ & $1.231 \mathrm{~b}$ & $14,20 \mathrm{f}$ & $4,44 \mathrm{a}$ & $3,44 a$ & $10,7 \mathrm{a}$ & $0,70 \mathrm{~b}$ & $16,20 \mathrm{c}$ & $72,1 b$ & $21,3 b$ & $4,39 a$ & 2 \\
\hline CFE 74 - FC 154 & $88,1 \mathrm{~b}$ & $1.288 \mathrm{a}$ & $15,40 \mathrm{e}$ & $3,11 b$ & $2,77 \mathrm{a}$ & $10,7 \mathrm{a}$ & $0,97 \mathrm{a}$ & $22,97 b$ & $89,2 \mathrm{a}$ & $22,3 a$ & $4,87 \mathrm{a}$ & 2 \\
\hline CFE $76-$ FC 149 & $87,1 \mathrm{c}$ & $1.326 \mathrm{a}$ & $16,80 \mathrm{e}$ & $4,11 b$ & $2,77 \mathrm{a}$ & $12,3 \mathrm{a}$ & $0,80 \mathrm{~b}$ & $12,26 \mathrm{c}$ & $56,3 \mathrm{~b}$ & $22,9 a$ & $4,27 \mathrm{a}$ & 2 \\
\hline CFE $77-$ FC 124 & $88,1 \mathrm{~b}$ & $1.430 \mathrm{a}$ & $18,40 \mathrm{~d}$ & $3,11 \mathrm{~b}$ & $3,11 \mathrm{a}$ & $10,9 a$ & $0,91 \mathrm{a}$ & $17,40 \mathrm{c}$ & $82,7 \mathrm{a}$ & $21,1 b$ & $3,97 \mathrm{a}$ & 2 \\
\hline CFE $84-\mathrm{FC} 16$ & $86,5 \mathrm{c}$ & $1.330 \mathrm{a}$ & $14,60 \mathrm{f}$ & $3,11 b$ & $3,44 a$ & $10,3 \mathrm{a}$ & $0,79 b$ & $15,20 \mathrm{c}$ & $74,5 b$ & $21,3 b$ & $4,36 \mathrm{a}$ & 2 \\
\hline CFE 86 - FC 94 & $88,5 b$ & $1.266 \mathrm{a}$ & $20,10 b$ & $4,11 b$ & $3,44 a$ & $11,6 \mathrm{a}$ & $0,94 a$ & $16,53 \mathrm{c}$ & $73,3 b$ & $21,3 b$ & $3,85 \mathrm{a}$ & 2 \\
\hline CFE $87-$ FC 135 & $88,1 \mathrm{~b}$ & $1.352 \mathrm{a}$ & $17,10 \mathrm{~d}$ & $4,44 \mathrm{a}$ & $3,44 a$ & $10,6 \mathrm{a}$ & $0,85 \mathrm{a}$ & $12,26 \mathrm{c}$ & $54,5 b$ & $22,4 a$ & $4,07 \mathrm{a}$ & 2 \\
\hline CFE 117 - FC 156 & $89,1 \mathrm{a}$ & $849 b$ & $14,50 \mathrm{f}$ & $3,88 \mathrm{~b}$ & $2,88 \mathrm{a}$ & $10,3 \mathrm{a}$ & $1,01 \mathrm{a}$ & $20,26 b$ & $110,7 \mathrm{a}$ & $21,1 b$ & $4,39 a$ & 2 \\
\hline CFE 115 - Bolinha & $88,8 \mathrm{~b}$ & $976 b$ & $18,20 \mathrm{~d}$ & $3,88 \mathrm{~b}$ & $2,88 \mathrm{a}$ & $10,8 \mathrm{a}$ & $0,81 b$ & $9,06 \mathrm{c}$ & $44,4 \mathrm{~b}$ & $22,1 \mathrm{a}$ & $5,01 \mathrm{a}$ & 2 \\
\hline CFE 110 - FC 139 & $86,5 \mathrm{c}$ & $923 b$ & $16,90 \mathrm{~d}$ & $3,88 \mathrm{~b}$ & $3,22 \mathrm{a}$ & $10,1 \mathrm{a}$ & $0,97 \mathrm{a}$ & $18,40 \mathrm{c}$ & $84,7 \mathrm{a}$ & $22,0 \mathrm{a}$ & $4,82 \mathrm{a}$ & 2 \\
\hline CFE $95-$ FC 109 & $85,8 \mathrm{c}$ & $1.059 \mathrm{~b}$ & $14,30 \mathrm{f}$ & $4,77 \mathrm{a}$ & $3,55 \mathrm{a}$ & $10,5 \mathrm{a}$ & $0,90 \mathrm{a}$ & $13,83 \mathrm{c}$ & $69,8 \mathrm{~b}$ & $22,8 \mathrm{a}$ & $4,56 \mathrm{a}$ & 2 \\
\hline CFE $96-$ FC 179 & $87,5 \mathrm{c}$ & $1.394 \mathrm{a}$ & $15,50 \mathrm{e}$ & $3,88 \mathrm{~b}$ & $2,88 \mathrm{a}$ & $10,2 \mathrm{a}$ & $0,90 \mathrm{a}$ & $16,23 \mathrm{c}$ & $74,4 b$ & $22,4 a$ & $4,31 \mathrm{a}$ & 2 \\
\hline CFE 97 - FC 133 & $89,8 \mathrm{a}$ & $983 b$ & $18,00 \mathrm{~d}$ & $3,55 \mathrm{~b}$ & $2.55 \mathrm{a}$ & $11,1 \mathrm{a}$ & $0,99 a$ & $11,46 \mathrm{c}$ & $52,2 \mathrm{~b}$ & $22,7 a$ & $4,51 \mathrm{a}$ & 2 \\
\hline CFE 100 - FC 113 & $86,2 \mathrm{c}$ & $1.463 \mathrm{a}$ & $27,80 \mathrm{a}$ & $4,22 b$ & $3,22 \mathrm{a}$ & $10,5 \mathrm{a}$ & $0,73 b$ & $11,93 \mathrm{c}$ & $51,2 \mathrm{~b}$ & $20,3 b$ & $4,28 \mathrm{a}$ & 2 \\
\hline CFE 103 - FC 87 & $87,5 \mathrm{c}$ & $1.400 \mathrm{a}$ & $16,60 \mathrm{e}$ & $3,88 \mathrm{~b}$ & $2,88 \mathrm{a}$ & $10,3 \mathrm{a}$ & $0,88 \mathrm{a}$ & $13,67 \mathrm{c}$ & $70,1 b$ & $21,7 \mathrm{a}$ & $4,07 \mathrm{a}$ & 2 \\
\hline CFE 106 - FC 61 & $86,8 \mathrm{c}$ & $1.275 \mathrm{a}$ & $16,20 \mathrm{e}$ & $4,22 b$ & $2,88 \mathrm{a}$ & $9,6 \mathrm{a}$ & $0,87 \mathrm{a}$ & $12,00 \mathrm{c}$ & $55,6 \mathrm{~b}$ & $20,8 b$ & $4,00 \mathrm{a}$ & 2 \\
\hline CFE 116 - FC 164 & $86,8 \mathrm{c}$ & $1.315 \mathrm{a}$ & $15,20 \mathrm{f}$ & $4,55 \mathrm{a}$ & $3,22 \mathrm{a}$ & $10,1 \mathrm{a}$ & $0,71 b$ & $16,40 \mathrm{c}$ & $72,8 b$ & $21,1 b$ & $4,73 \mathrm{a}$ & 2 \\
\hline FT Nobre & $87,6 \mathrm{c}$ & $1.303 \mathrm{a}$ & $15,80 \mathrm{f}$ & $4,77 \mathrm{a}$ & $3,00 \mathrm{a}$ & $10,6 \mathrm{a}$ & $0,74 b$ & $16,13 \mathrm{c}$ & $71,9 b$ & $21,7 \mathrm{a}$ & $4,26 \mathrm{a}$ & 2 \\
\hline CFE 07 - FC 2053 & $86,5 \mathrm{c}$ & $1.407 \mathrm{a}$ & $16,20 \mathrm{e}$ & $4,77 \mathrm{a}$ & $3,11 \mathrm{a}$ & $10,5 \mathrm{a}$ & $0,73 \mathrm{a}$ & $18,06 \mathrm{c}$ & $84,1 \mathrm{a}$ & $19,6 \mathrm{~b}$ & $4,45 \mathrm{a}$ & 3 \\
\hline CFE 79 - manteiga & $87,1 \mathrm{c}$ & $1.400 \mathrm{a}$ & $16,60 \mathrm{e}$ & $3,11 \mathrm{~b}$ & $2,77 \mathrm{a}$ & $10,6 \mathrm{a}$ & $0,85 \mathrm{a}$ & $14,80 \mathrm{c}$ & $63,3 b$ & $20,7 b$ & $4,45 \mathrm{a}$ & 3 \\
\hline CFE 108 - Turrialba & $86,2 \mathrm{c}$ & $1172 b$ & $17,10 \mathrm{~d}$ & $3,88 \mathrm{~b}$ & $3,22 \mathrm{a}$ & $9,4 a$ & $0,98 \mathrm{a}$ & $16,27 \mathrm{c}$ & $70,6 b$ & $21,2 b$ & $4,00 \mathrm{a}$ & 3 \\
\hline CFE 109 - FC 139 & $89,3 \mathrm{a}$ & $1.183 b$ & $18,00 \mathrm{~d}$ & $3,88 b$ & $3,22 \mathrm{a}$ & $11,4 \mathrm{a}$ & $0,71 \mathrm{a}$ & $12,33 \mathrm{c}$ & $59,5 \mathrm{~b}$ & $20,9 b$ & $4,49 a$ & 3 \\
\hline CFE 89 - FC 1166 & $87,5 \mathrm{c}$ & $1.338 \mathrm{a}$ & $16,60 \mathrm{e}$ & $4,77 \mathrm{a}$ & $3,11 \mathrm{a}$ & $10,6 \mathrm{a}$ & $0,83 b$ & $16,80 \mathrm{c}$ & $82,7 \mathrm{a}$ & $20,9 b$ & $4,24 a$ & 4 \\
\hline CFE 129 - FC 137 & $86,8 \mathrm{c}$ & $1.371 \mathrm{a}$ & $16,20 \mathrm{e}$ & $4,22 b$ & $2,88 \mathrm{a}$ & $10,5 \mathrm{a}$ & $0,72 b$ & $16,67 \mathrm{c}$ & $79,9 b$ & $20,0 b$ & $4,31 \mathrm{a}$ & 4 \\
\hline EMPASC 201 & $86,0 \mathrm{c}$ & $1.584 \mathrm{a}$ & $16,20 \mathrm{e}$ & $4,33 \mathrm{a}$ & $3,16 a$ & $10,9 a$ & $0,76 \mathrm{~b}$ & $16,53 \mathrm{c}$ & $84,8 \mathrm{a}$ & $20,9 b$ & $4,19 a$ & 4 \\
\hline CFE $75-$ FC 1158 & $87,5 \mathrm{c}$ & $1.541 \mathrm{a}$ & $23,70 \mathrm{~b}$ & $4,11 \mathrm{~b}$ & $3,44 a$ & $10,6 \mathrm{a}$ & $1,01 \mathrm{a}$ & $25,46 b$ & $110,1 \mathrm{a}$ & $21,3 b$ & $4,61 \mathrm{a}$ & 5 \\
\hline CFE 118 - FC 177 & $85,8 \mathrm{c}$ & $903 b$ & $13,50 \mathrm{f}$ & $4,22 b$ & $3,22 \mathrm{a}$ & $10,5 \mathrm{a}$ & $0,86 a$ & $13,67 \mathrm{c}$ & $65,5 b$ & $22,4 \mathrm{a}$ & $4,80 \mathrm{a}$ & 5 \\
\hline CFE 102 & $86,2 \mathrm{c}$ & $1.488 \mathrm{a}$ & $17,20 \mathrm{~d}$ & $3,88 \mathrm{~b}$ & $2,88 \mathrm{a}$ & $10,2 \mathrm{a}$ & $0,95 \mathrm{a}$ & $21,93 b$ & $106,8 \mathrm{a}$ & $21,2 b$ & $4,02 \mathrm{a}$ & 5 \\
\hline CFE 18 - FC 2044 & $86,8 \mathrm{c}$ & $1.612 \mathrm{a}$ & $18,10 \mathrm{~d}$ & $4,11 b$ & $2,77 \mathrm{a}$ & $10,3 \mathrm{a}$ & $0,93 a$ & $13,53 \mathrm{c}$ & $99,5 \mathrm{a}$ & $19,6 b$ & $4,13 \mathrm{a}$ & 6 \\
\hline CFE 82 - manteiga & $88,8 \mathrm{~b}$ & $1.260 \mathrm{a}$ & $15,10 \mathrm{f}$ & $3,44 b$ & $3,11 \mathrm{a}$ & $11,2 \mathrm{a}$ & $0,90 \mathrm{a}$ & $24,00 \mathrm{~b}$ & $92,6 a$ & $21,9 a$ & $4,50 \mathrm{a}$ & 6 \\
\hline CFE93-Copinha & $87,2 \mathrm{c}$ & $1.219 \mathrm{~b}$ & $15,60 \mathrm{e}$ & $3,22 b$ & $2,88 \mathrm{a}$ & $10,3 \mathrm{a}$ & $0,72 b$ & $15,06 \mathrm{c}$ & $73,5 b$ & $21,5 \mathrm{a}$ & $3,98 \mathrm{a}$ & 6 \\
\hline CFE 112 - FC 170 & $89,8 \mathrm{a}$ & $1.070 \mathrm{~b}$ & $7,60 \mathrm{e}$ & $3,55 b$ & $2,88 \mathrm{a}$ & $11,0 \mathrm{a}$ & $0,80 \mathrm{~b}$ & $19,63 b$ & $91,4 \mathrm{a}$ & $20,2 b$ & $4,27 \mathrm{a}$ & 6 \\
\hline CFE 22 - FC 2028 & $86,5 \mathrm{c}$ & $1.387 \mathrm{a}$ & $15,90 \mathrm{e}$ & $4,77 \mathrm{a}$ & $3,44 a$ & $11,6 \mathrm{a}$ & $0,74 b$ & $16,20 \mathrm{c}$ & $76,1 b$ & $20,6 b$ & $4,53 \mathrm{a}$ & 7 \\
\hline CFE $83-$ FC 129 & $88,5 b$ & $1.462 \mathrm{a}$ & $17,40 \mathrm{~d}$ & $4,11 b$ & $2,77 \mathrm{a}$ & $11,0 \mathrm{a}$ & $0,89 a$ & $17,26 \mathrm{c}$ & $70,5 b$ & $22,0 \mathrm{a}$ & $4,73 a$ & 7 \\
\hline CFE $94-$ FC 93 & $86,8 \mathrm{c}$ & $1.653 \mathrm{a}$ & $16,50 \mathrm{e}$ & $3,88 \mathrm{~b}$ & $2,88 \mathrm{a}$ & $10,6 \mathrm{a}$ & $0,82 b$ & $19,53 b$ & $105,4 \mathrm{a}$ & $21,3 b$ & $3,30 \mathrm{a}$ & 7 \\
\hline CFE 113 - Taquara & $88,2 b$ & $1.479 \mathrm{a}$ & $18,20 \mathrm{~d}$ & $3,22 b$ & $2,88 \mathrm{a}$ & $10,3 \mathrm{a}$ & $0,78 b$ & $17,46 \mathrm{c}$ & $67,1 b$ & $22,6 a$ & $4,17 \mathrm{a}$ & 7 \\
\hline Diamante Negro & $86,8 \mathrm{c}$ & $1.399 \mathrm{a}$ & $16,50 \mathrm{e}$ & $4,00 \mathrm{~b}$ & $2,83 a$ & $9,8 \mathrm{a}$ & $0,78 b$ & $15,06 \mathrm{c}$ & $71,3 b$ & $21,5 \mathrm{a}$ & $4,40 \mathrm{a}$ & 8 \\
\hline CFE 61 - FC 2041 & $86,8 \mathrm{c}$ & $786 \mathrm{~b}$ & $23,40 \mathrm{~b}$ & $4,77 \mathrm{a}$ & $3,44 \mathrm{a}$ & $10,7 \mathrm{a}$ & $0,97 \mathrm{a}$ & $14,20 \mathrm{c}$ & $49,1 \mathrm{~b}$ & $22,2 \mathrm{a}$ & $4,12 \mathrm{a}$ & 9 \\
\hline Média & 87,4 & 1.320 & 17,29 & 4,09 & 3,10 & 10,63 & 0,86 & 16,58 & 76,89 & 21,38 & 4,37 & \\
\hline $\mathrm{CV}(\%)$ & 1,02 & 15,95 & 4,20 & 13,7 & 17,3 & 7,0 & 15,4 & 22,56 & 20,2 & 5,1 & 10,1 & \\
\hline
\end{tabular}

${ }^{(1)} \mathrm{DM}$ : dias para maturação; Prod: rendimento de grãos; P100: peso de 100 grãos; Bac: reação à bacteriose; Antr: reação à antracnose, CF: comprimento do folíolo; AP: altura da planta; NVP: número de vagens por planta; NSP: número de sementes por planta; PB: proteína bruta; FB: fibra bruta; médias seguidas pela mesma letra na coluna não diferem entre si a 5\% de probabilidade, pelo teste de Scott-Knott. 
O agrupamento das cultivares pelo método de Tocher foi realizado utilizando-se as distâncias genéticas entre os pares de cultivares. Este método tem como princípio manter a homogeneidade dentro e heterogeneidade entre os grupos, e possibilitou a reunião das cultivares em nove grupos distintos (Tabela 2).

Vale ressaltar a proximidade genética entre a testemunha FT Nobre e as cultivares tradicionais 1 (CFE 02), 6 (CFE 25), 7 (CFE 29), 8 (CFE 34), 10 (CFE 74), 12 (CFE 76), 13 (CFE 77), 18 (CFE 84), 19 (CFE 86), 20 (CFE 87), 22 (CFE 117), 24 (CFE 115), 25 (CFE 110), 30 (CFE 95), 31 (CFE 96), 32 (CFE 97), 34 (CFE 100), 36 (CFE 103), 37 (CFE 106) e 42 (CFE 116), incluídas no mesmo grupo 2 na análise de Tocher (Tabela 2). A menor distância identificada entre todos os pares avaliados foi entre os acessos CFE 80 e CFE 111. Estes resultados sugerem que essas cultivares podem ser consideradas aparentadas.

Em relação às cultivares mais dissimilares, observouse que a cultivar CFE 22 (grupo 7), quando comparada às 44 demais cultivares, foi apontada como mais distante em 39 casos. Este fato é comprovado no dendrograma pelo método de agrupamento UPGMA (Figura 1), no qual é possível visualizar claramente as cultivares do grupo 7, bastante dissimilares das demais. Caso seja traçada uma reta em $30 \%$ de divergência, serão formados apenas dois grupos (Figura 1). Há de se considerar essa grande divergência relativa, no grupo avaliado, na realização de cruzamentos.

A variabilidade genética de uma população segregante depende da divergência genética e dos pais envolvidos no cruzamento (Falconer, 1987). Entretanto, se o objetivo do programa é aumentar a produtividade, devem-se escolher, para cruzamentos, cultivares de boa performance per se, que apresentem maior distância genética ou que complementem alguma característica de um dos genitores.

No entanto, apesar de ser muito enfatizada a importância da divergência genética na escolha de genitores em programas de melhoramento por hibridação, ainda é discutível a relação entre a divergência de progenitores e o potencial produtivo em seus híbridos. Melo et al. (2001), em estudos com milho, não evidenciaram relação entre divergência genética, medida pela distância de Mahalanobis, e a heterose para produtividade de grãos. Entretanto, Cruz (1990), em milho,

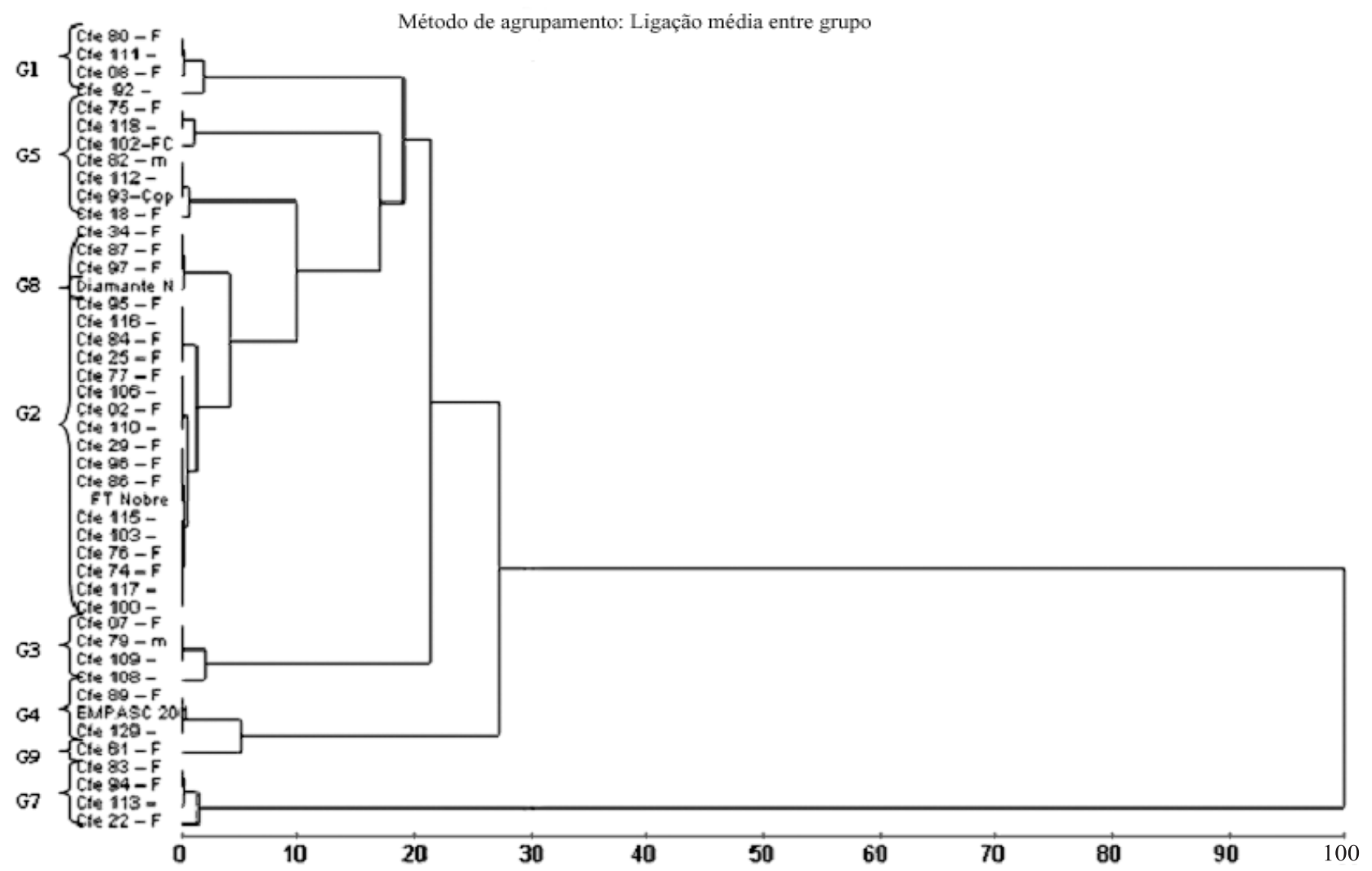

Figura 1. Dendrograma construído a partir das distâncias de Mahalanobis ( $\left.\mathrm{D}^{2}\right)$. 
verificou uma relação positiva entre diversidade nos progenitores e heterose nos híbridos.

Apesar da diversidade constatada entre as cultivares, de modo geral, interessam aos melhoristas apenas as cultivares superiores em relação às características mais importantes e que apresentem divergência suficiente para gerar variabilidade nas populações segregantes. Desta forma, as cultivares CFE 25, CFE 100 e FT Nobre (grupo 2) destacaram-se, apresentando médias superiores em pelo menos seis das características estudadas (Tabela 2). Essas cultivares também se destacaram por apresentar menor estatura de plantas, $\mathrm{e}$, conseqüentemente, porte ereto, à semelhança da cultivar FT Nobre (hábito de crescimento tipo II). O cruzamento entre essas cultivares com outras de grupos distintos, pode, portanto, aliar cultivares divergentes e média em produtividade elevada. Da mesma forma, a cultivar CFE 25 e CFE 100, ambas com produção e massa de 100 grãos elevados, poderão ser utilizadas num programa de cruzamentos com cultivares do grupo 4 , divergentes e com médias elevadas para as principais características de interesse, em especial rendimento de grãos. A testemunha FT Nobre pode ser indicada, também, para cruzamento com cultivares de outros grupos, procurando elevar produção e massa de grãos, bem como proteína bruta.

A cultivar Diamante Negro constituiu isoladamente o grupo 8 , sendo, portanto, divergente em relação às demais. Ela apresentou elevada média para Prod, PB, menor DM, e baixo AP, com porte ereto ou semi-ereto. Sendo assim, esta cultivar poderá participar de cruzamentos artificiais com outras cultivares de grupos distintos, de preferência também de média elevada para estas características.

Considerando que as cultivares melhoradas Diamante Negro e FT Nobre apresentaram significativas distâncias em relação às cultivares tradicionais, ressalta-se sua importância para uso em programas de melhoramento, pelo possível aporte de novas combinações alélicas. A distância entre as cultivares melhoradas e as tradicionais de outros grupos sugere que a exploração de populações híbridas derivadas do intercruzamento de seus integrantes poderá levar ao surgimento de interessantes recombinações. Fato também observado no Sul do Brasil por Rodrigues et al. (2002).

Os indicativos para realização de cruzamentos artificiais entre as cultivares com maior divergência genética e com boa produtividade geram em torno de 30 cruzamentos promissores, número bem inferior ao número total de combinações possíveis entre as 45 cultivares avaliadas, que totaliza 990.

\section{Conclusões}

1. Há divergência genética entre as cultivares tradicionais e as testemunhas comerciais de feijão do grupo preto.

2. O cruzamento entre as cultivares do grupo 2, em especial CFE 25, CFE 100 e FT Nobre, e as do grupo 7, com destaque para a cultivar CFE 22, apresentam grande potencial.

3. A cultivar Diamante Negro deve ser utilizada em cruzamentos com essas cultivares por ser a mais divergente e possuir elevada produtividade.

\section{Referências}

AMARAL JÚNIOR, A.T. Análise dialélica de betacaroteno, vitamina $C$, sólidos solúveis e produção e variabilidade em cultivares de tomateiro (Lycopersicon esculentum Mill.) via marcadores RAPD. 1996. 198p. Tese (Doutorado) - Universidade Federal de Viçosa, Viçosa.

BENIN, G; CARVALHO, F.I. de; ASSMANN, I.C.; CIGOLINI, J.; CRUZ, P.J.; MARCHIORO, V.S.; LORENCETTI, C.; SILVA, J.A.G. Identificação da dissimilaridade genética entre genótipos de feijoeiro comum (Phaseolus vulgaris L.) do grupo preto. Revista Brasileira de Agrociência, v.8, p.179-184, 2002.

BONETT, L.P.; GONÇALVES-VIDIGAL, M.C.; SCHUELTER, A.R.; VIDIGAL FILHO, P.S.; GONELA, A.; LACANALLO, G.F. Divergência genética em germoplasma de feijoeiro comum coletado no Estado do Paraná, Brasil. Semina: Ciências Agrárias, v.27, p.547-560, 2006.

CEOLIN, A.C.G; GONÇALVES-VIDIGAL, M.C.; VIDIGALFILHO, P.S.; KVITSCHAL, M.V.; GONELA, A.; SCAPIM, C.A. Genetic divergence of the common bean (Phaseolus vulgaris L.) group Carioca using morpho-agronomic traits by multivariate analysis. Hereditas, v.144, p.1-9, 2007.

CRUZ, C.D. Aplicação de algumas técnicas multivariadas no melhoramento de plantas. 1990. 188p. Tese (Doutorado) Universidade de São Paulo, Piracicaba.

CRUZ, C.D.; CARNEIRO, P.C.S. Modelos biométricos aplicados ao melhoramento genético. Viçosa: UFV, 2003. v.2. 585p.

CRUZ, C.D.; REGAZZI, A.J. Modelos biométricos aplicados ao melhoramento. 2.ed. Viçosa: UFV, 1997. 390p.

DUDLEY, J.W. Comparison of genetic distance estimators using molecular marker data. In: SYMPOSIUM ANALYS OF MOLECULAR DATA, 2., 1994, Corvallis. Proceedings. Corvallis: American Society for Horticultural Science; Crop Science Society of America, 1994. p.3-7.

EMYGDIO, B.M.; ANTUNES, I.F.; CHOER, E.; NEDEL, J.L. Eficiência de coeficientes de similaridade em genótipos de feijão mediante 
marcadores RAPD. Pesquisa Agropecuária Brasileira, v.38, p.243250, 2003.

EPAGRI. Recomendações técnicas para a cultura do feijão em Santa Catarina. Florianópolis: Epagri, 1997. 70p. (Epagri. Sistemas de produção, 29).

FALCONER, D.S. Introdução à genética quantitativa. Viçosa: UFV, 1987. 279p.

FAO. Faostat. Roma: FAO, 2005. Disponível em: http:// faostat.fao.org. Acesso em: 3 set. 2005.

FERREIRA, D.F. Métodos de avaliação da divergência genética em milho e suas relações com os cruzamentos dialélicos. 1993. 72p. Dissertação (Mestrado) - Universidade Federal de Lavras, Lavras, 1993.

FRANCO, M.C.; CASSINI, S.T.A.; OLIVEIRA, V.R.; TSAI, S.M. Caracterização da diversidade genética em feijão por meio de marcadores RAPD. Pesquisa Agropecuária Brasileira, v.36, p.381$385,2001$.

GHADERI, A.; ADAMS, M.W.; NASSIB, A.M. Relationship between genetic distance and heterosis for yield and morphological traits in dry edible bean and fava bean. Crop Science, v.14, p.24-27, 1984.

MACHADO, C. de F.; NUNES, G.H.S.; FERREIRA, D.F.; SANTOS, J.B. Divergência genética entre genótipos de feijoeiro a partir de técnicas multivariadas. Ciência Rural, v.32, p.251-258, 2002 .

MELO, W.M.C.; PINHO, R.G.V.; FERREIRA, D.F. Capacidade combinatória e divergência genética em híbridos comerciais de milho. Ciência e Agrotécnica, v.25, p.821-830, 2001.
PEIXOTO, N.; BRAZ, L.T.; BANZATTO, D.A.; MORAES, E.A.; MOREIRA, F.M. Características agronômicas, produtividade, qualidade de vagens e divergência genética em feijão-vagem de crescimento indeterminado. Horticultura Brasileira, v.20, p.447451, 2002.

RIBEIRO, N.D.; MELLO, R.M.; DALLA COSTA, R.; SLUSSZ, T. Correlações genéticas de caracteres agromorfológicos e suas implicações na seleção de genótipos de feijão carioca. Revista Brasileira de Agrociência, v.7, p.93-99, 2001.

RODRIGUES, L.S.; ANTUNES, I.F.; TEIXEIRA, M.G.; SILVA, J.B. Divergência genética entre cultivares locais e cultivares melhoradas de feijão. Pesquisa Agropecuária Brasileira, v.37, p.1275-1284, 2002.

SANTOS, V.S. Seleção de pré-cultivares de soja baseada em índices. 2005. 104p. Tese (Doutorado) - Universidade de São Paulo, Piracicaba.

SCAPIM, C.A.; PIRES, I.E.; CRUZ, C.D.; AMARAL JUNIOR, A.T.; BRACCINI, A. e L.; OLIVEIRA, V.R. Avaliação da diversidade genética em Eucalyptus camaldulensis Dehnh, por meio da análise multivariada. Revista Ceres, v.6, p.347-356, 1999.

SILVA, V.R.; IACHAN, A. Proteínas de variedades brasileiras de feijão ( $P$. vulgaris). I- quantificação e fracionamento das proteínas. Revista Brasileira de Tecnologia, v.6, p.133-141, 1975.

SINGH, S. Patterns of variation in cultivated common bean (Phaseolus vulgaris, Fabaceae). Economic Botany, v.43, p.39-57, 1989.

VIDIGAL FILHO, P.S.; ROCHA, A.B.; HAMMERSCHMIDT, R.; KIRK, W.W. Total soluble amino acids and protein content of landrace common bean (Phaseolus vulgaris L.) cultivars collected in Parana State, Brazil. Annual Report of the Bean Improvement Cooperative, v.46, p.61-62. 2003. 